\title{
PENGARUH DISIPLIN KERJA TERHADAP KINERJA PEGAWAI DI BIRO PELAYANAN SOSIAL DASAR SEKRETARIAT DAERAH PROVINSI JAWA BARAT
}

\author{
Astadi Pangarso, Putri Intan Susanti \\ Universitas Telkom \\ E-mail: astadipangarso@telkomuniversity.ac.id, putriintans07@yahoo.com
}

\begin{abstract}
Bureau of Social Services in West Java Provinces has a fundamental duty organize formulation of general policy and coordination, reporting and evaluation of religion, education and culture, health and the environment. Employees have an important role in carrying out the task of the Bureau of Social Services. Implementation of discipline for employees has a function to improve employee performance. The Problems of this bureau is the declining performance of employees in 2015 due to lack of work discipline on Bureau of Social Services in West Java Regional. The effort to improve employee performance with these problems is suspected factors work discipline that has an influence on employee performance. Work discipline has a very high influence in the creation of employee performance Bureau of Social Services in West Java Regional, the value of $R$ (correlation) produced is 0,745 , it can be said that the discipline of work and employee performance are positively related $74.5 \%$, While the coefficient of determination R2 ( $R$ Square) is 0.554 , which means the ability to work discipline variable in influencing the performance of employees in the Bureau of Social Services in West Java Regional amounted to $55.4 \%$, while $44.6 \%$ is the contribution of other factors which was not observed in this study. Employee performance $(Y)$ can be explained by the discipline of work through regression $Y=0,646+0,849 X$. This shows the influence of employee discipline $(X)$ on employee performance $(Y)$ is positive at 0,849 , thus if the variable work discipline has increased 0,849 then the variable performance of employees will also increase number of 0,646.
\end{abstract}

Keywords: Discipline Work, Employee Performance, Correlation, Bureau of Social Services. 


\section{Astadi Pangarso}

\section{Putri Intan Susanti}

\section{PENDAHULUAN}

Salah satu langkah strategis untuk mengembangkan kemampuan organisasi yang terdapat pada Pemerintah Daerah yakni upaya penyempurnaan perilaku manusia sebagai sumber daya yang memegang peranan penting dalam menyelenggarakan tugas-tugas Pemerintah, sehingga semua tugas dapat terlaksana secara efektif, efisien, dan produktif.

Kinerja merupakan landasan bagi pencapaian tujuan suatu organisasi.Keberhasilan organisasi dalam meningkatkan kinerjanya sangat bergantung pada kualitas sumber daya manusia yang bersangkutan dalam bekerja selama berada pada organisasi tersebut.Lebih lanjut, peranan sumber daya manusia terhadap kinerja organisasi sangatlah penting, keputusan-keputusan sumber daya manusia harus dapat meningkatkan efisiensi bahkan mampu memberikan peningkatan hasil organisasi serta berdampak pula pada peningkatan kepuasan masyarakat (Logahan 2009: 3).

Berdasarkan data yang tersedia dari kepegawaian, presentase kinerja karyawan pada tahun 2015 dapat dilihat dalam tabel berikut:

Tabel 1 Tabel rata-rata Presentase Kinerja Karyawan (\%) pada tahun 2015

\begin{tabular}{|l|l|}
\hline \multicolumn{1}{|c|}{ Bulan } & \multicolumn{1}{|c|}{ Pencapaian kinerja (\%) } \\
\hline Januari & 86 \\
Februari & 87 \\
Maret & 90 \\
April & 87,5 \\
Mei & 88 \\
Juni & 87 \\
Juli & 85,5 \\
Agustus & 86 \\
September & 88 \\
Oktober & 87,5 \\
November & 87 \\
Desember & 89 \\
\hline Rata-rata & 87,5 \\
\hline
\end{tabular}

Sumber: Data internal bagian kepegawaian sekretariat daerah Provinsi Jawa Barat (Januari Desember 2015).

Berdasarkan tabel 1 penilaian kinerja karyawan pada biro yayasan sosial dasar jika dibandingkan dengan peraturan pemerintah republik Indonesia tentang penilaian pelaksanaan pekerjaan pegawai negri sipil kriteria interpretasi skor untuk variable kinerja pegawai dapat dikatagorikan tergolong baik. Nilai rata-rata dari kinerja dalam satu tahun adalah $87,5 \%$ walaupun demikian setiap badan atau organisasi ataupun perusahaan menginginkan presentase kinerja karyawannya diatas 95\% (mendekati 100\%).

Menurut peraturan pemerintah repubublik Indonesia no.10 Tahun 1979 tentang penilaian pelaksanaan pekerjaan pegawai negri sipil dalam BAB II (daftar penilaian pelaksanaan pekerjaan) pasal 5, nilai pelaksanaan pekerjaan di nyatakan dengan sebutan dan angka sebagai berikut: 


\section{Tabel 2 Nilai pelaksanaan kinerja dalam PP NO. 46 Tahun 2011}

\begin{tabular}{|ll|}
\hline Amat Baik & $91-100$ \\
\hline Baik & $76-90$ \\
\hline Cukup & $61-75$ \\
\hline Sedang & $51-60$ \\
\hline Kurang & $50-$ kebawah \\
\hline
\end{tabular}

Sesuai tabel nilai pelaksanaan kinerja pegawai, kondisi ini masuk dalam katagori baik.Peranan tersebut tidak terlepas dari upaya positif yang dilakukan dalam mendapatkannya sebagai wujud dari pencapaian tujuan utama suatu organisasi.

Banyak faktor yang dapat mempengaruhi kinerja, antara lain motivasi, kepemimpinan, lingkungan kerja, disiplin kerja, budaya kerja, komunikasi, komitmen, jabatan, kualitas kehidupan kerja, pelatihan, kompensasi, kepuasan kerja, dan masih banyak yang lain. Semua faktor tersebut berpengaruh, tergantung pada fakta yang terjadi sebenarnya, ada yang dominan dan ada pula yang tidak (Wahyudin 2006: 2).Dalam penelitian ini, faktor kedisiplinan menjadi fokus faktor utama yang dapat mempengaruhi kinerja.Berdasarkan penelitian yang telah dilakukan (Pangarso 2014) tentang disiplin karyawan menjadi bagian yang turut berkontribusi bagi latar belakang penelitian ini dalam konteks pentingnya topik tentang disiplin karyawan.

Disiplin merupakan tindakan manajemen untuk mendorong para anggota organisasi guna memenuhi berbagai ketentuan.Dalam penerapannya, disiplin lebih ditekankan pada unsur kesadaran individu untuk mengikuti peraturan- peraturan yang berlaku dalam organisasi (Susilaningsih, 2008: 3). Namun berbeda dengan penelitian yang dilakukan oleh Raharjo (2012: 7) yang menunjukkan bahwa variabel disiplin kerja berpengaruh terhadap variabel kinerja pegawai. Dalam hal ini, kedisiplinan penting bagi organisasi sebab akan ditaati oleh sebagian besar pegawai dan diharapkan pekerjaan akan dilakukan secara efektif.

Penerapan disiplin bagi karyawan diharapkan dapat meningkatkan kinerja karyawan. Disamping itu perlu didukung lingkungan kerja yang baik berupa lingkungan kerja yang dapat menunjang kelancaran, keamanan, keselamatan, kebersihan, serta kenyamanan dalam bekerja dan adanya fasilitas yang memadai sehingga karyawan merasa aman, tenang dan senang dalam menjalankan tugas- tugas yang dibebankan dan menjadi tanggung jawabnya (Suprayitno 2007: 24).

Salah satu faktor yang mempengaruhi disiplin kerja menurut Hasibuan (2000: 195) adalah hubungan kerja yang erat dan saling membantu antar sesama karyawan, dan antara karyawan dengan pimpinan akan mempunyai pengaruh yang baik terhadap kepuasan kerja pegawai dan berujung pada output kinerja yang baik pula. Faktor tersebut inilah yang diharapkan mampu memberikan pelayanan prima sehingga memiliki nilai tambah atas pelayanan dari Instansi tersebut.

Semua Instansi pasti memerlukan manajemen yang berkaitan dengan upaya-upaya guna pencapaian tujuan.Tidak hanya pada sektor swasta, sektor publik juga memerlukan manajemen yang baik agar dapat memberikan pelayanan kepada masyarakat yang baik 


\section{Astadi Pangarso}

\section{Putri Intan Susanti}

pula.Berhasil atau tidaknya suatu organisasi dalam mencapai tujuannya tergantung pada tingkat keberhasilan dari tiap individu organisasi itu sendiri dalam menjalankan tugas mereka (Wahyuddin, 2006: 1).

Penelitian ini akan mengkaji bagaimana pengaruh disiplin kerja terhadap kinerja karyawan. Bagi organisasi yang memberikan pelayanan publik, tentu saja kinerja karyawan itu dapat dilihat dari bagaimana organisasi tersebut dalam memberikan pelayanan kepada publik, seperti dalam Sekretariat Daerah Provinsi Jawa Barat yang memberikan pelayanan berkaitan dengan masyarakat.

Berdasarkan permasalahan tersebut maka dirumuskan suatu pertanyaan penelitian sebagai berikut:

Apakah disiplin kerja berpengaruh terhadap kinerja karyawan pada Biro pelayanan sosial dasar seketariat daerah Provinsi Jawa Barat?

\section{KERANGKA TEORITIS DAN PENGEMBANGAN HIPOTESIS}

Menurut Moenir (2004: 25) disiplin kerja pada dasarnya selalu diharapkan menjadi ciri setiap SDM dalam organisasi, karena dengan kedisiplinan organisasi akan berjalan dengan baik dan bisa mencapai tujuannya dengan baik pula. Setiap karyawan harus memiliki disiplin kerja didalam organisasi atau perusahaannya, seperti mematuhi peraturan tertulis maupun tidak tertulis yang telah di tetapkan oleh perusahaan karena hal tersebut dapat menciptakan lingkungan kerja yang kondusif dan harmonis sehingga akan memberikan dampak yang positif terhadap kinerja karyawannya. Berdasarkan hasil penelitian Syarif (2004: 56) tentang motivasi dan kinerja di lingkungan pemerintahan yag menyebutkan bahwa tidak optimalnya kinerja karyawan disebabkan oleh banyaknya karyawan bermotivasi buruk dalam kerja, juga banyaknya karyawan yang tidak disiplin dalam bekerja. Menurut Susiarto dan Ahmadi (2006: 40), disiplin kerja karyawan bagian dari faktor kinerja. Prasetyo (2008: 36) menyatakan bahwa salah satu faktor penentu dari efektifitas kinerja adalah disiplin kerja. Disiplin kerja harus dimiliki setiap karyawan dan harus dibudayakan di kalangan karyawan agar bisa mendukungtercapainya tujuan organisasi karena merupakan wujud dari kepatuhan terhadap aturan kerja dan juga sebagai tanggung jawab diri terhadap perusahaan.

Berdasarkan uraian diatas, maka hipotesis yang diajukan dalam penelitian ini adalah:

H1: Disiplin kerja karyawan berpengaruh postif terhadap kinerja karyawan. 


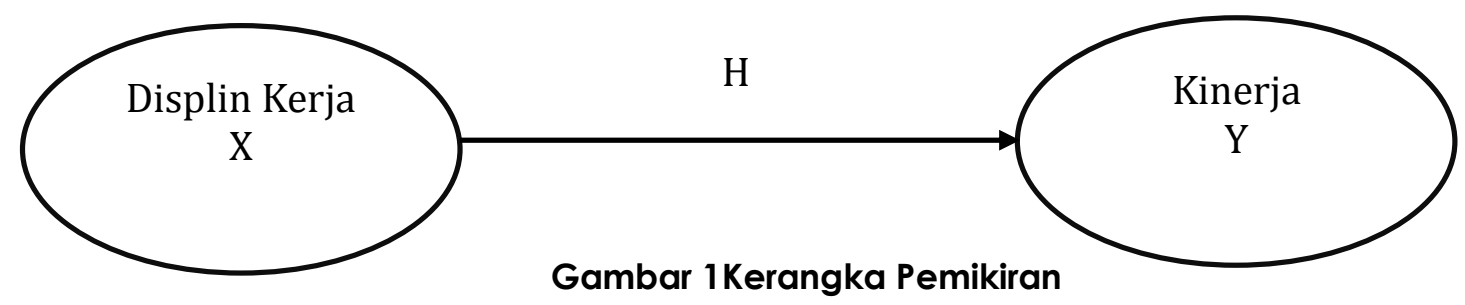

Hubungan variabel dalam menyelesaikan hipotesis diatas terdapat indikator untuk setiap variabelnya. Berikut adalah indikator untuk variabel displin berdasarkan literatur :

\section{Tabel 3 Indikator untuk Variabel Displin}

\begin{tabular}{|c|l|l|c|}
\hline No & Variable Disiplin Menurut & Indikator & Item dalam Kuesioner \\
\hline 1 & Hasibuan, 2012 & Kejelasan tujuan dan Beban Kerja & 1 \\
\hline & & Keteladanan Pemimpin & 2 \\
\hline & & Kepuasan terhadap balas jasa yang diberikan & 3 \\
\hline & & Adanya persamaan Hak dan Kewajiban & 4 \\
\hline & & Keaktifan pimpinan dalam melakukan pengawasan & 5 \\
\hline & & Pelaksanaan hukuman ketika melakukan kesalahan & 7 \\
\hline & & Penindakan yang konsisten dalam melaksanakan Peraturan & 8 \\
\hline & & Keharmonisan hubungan & 9 \\
\hline & & Mematuhi semua peraturan perusahaan & 10 \\
\hline & & Penggunaan waktu secara efektif & 11 \\
\hline
\end{tabular}

Pada variabel kinerja pun, terdapat perbandingan indikator untuk kinerja. Berikut adalah indikator untuk variabel kinerja berdasarkan literatur :

Tabel 4 Indikator untuk Variabe Kinerja

\begin{tabular}{|c|l|l|c|}
\hline No & Variable Kinerja Menurut & \multicolumn{1}{|c|}{ Indikator } & Item dalam Kuesioner \\
\hline 1 & Wilson Bangun, 2012 & Kemampuan dalam meningkatkan jumlah pekerjaan & 1 \\
\hline & & Kualitas pekerjaan yang dihasilkan & 2 \\
\hline & & Tepat waktu dalam meyelesaikan pekerjaan & 3 \\
\hline & & Kehadiran karyawan sesuai waktu yang ditentukan & 4 \\
\hline & & Kerjasama antar karyawan & 5 \\
\hline & & Kuantitas yang melebihi rata-rata & 6 \\
& & Kualitas yang lebih baik dari karyawan lain. & 7 \\
& & Standar karyawan yang melebihi standar resmi perusahaan & 8 \\
& & Pengetahuan karyawan yang berkaitan dengan pekerjaan & 9 \\
\hline
\end{tabular}

Hasil dari penentuan indikator tabel diatas, Indikator tersebut dapat digunakan untuk penentuan pertanyaan pada kuesioner yang akan mendukung penelitian ini. 


\section{Astadi Pangarso}

\section{Putri Intan Susanti}

\section{METODE PENELITIAN}

Populasi dalam penelitian ini adalah 64 orang pegawai di Biro Yayasan Sosial Sekretariat Daerah Provinsi Jawa Barat yang semuanya akan dijadikan subyek atau sampel dalam penelitian ini. Pada table 5 dapat dilihat populasi dalam penelitian ini:

Tabel 5 Sumber Daya Manusia Pada Biro Pelayanan Sosial Dasar Tahun 2013

\begin{tabular}{|c|l|l|l|l|l|l|l|l|l|}
\hline No & \multicolumn{3}{|c|}{ Golongan } & \multicolumn{3}{c|}{ Tingkat Pendidikan } & \multicolumn{3}{c|}{ Jenis Kelamin } \\
\hline 1 & Golongan IV & 9 & Orang & S3 & 2 & Orang & Pria & 44 & Orang \\
\hline 2 & Golongan III & 39 & Orang & S2 & 15 & Orang & Wanita & 20 & Orang \\
\hline 3 & Golongan II & 14 & Orang & S1 & 22 & Orang & & & \\
\hline 4 & Honorer & 2 & Orang & Diploma & 5 & Orang & & & \\
\hline 5 & & & & SLTA & 18 & Orang & & & \\
\hline 6 & & & & SLTP & 2 & Orang & & & \\
\hline 7 & & & & SD &.. & Orang & & & \\
\hline 8 & Jumlah & $\mathbf{6 4}$ & Orang & Jumlah & $\mathbf{6 4}$ & Orang & Jumlah & $\mathbf{6 4}$ & Orang \\
\hline \hline
\end{tabular}

Pengambilan sampel pada penelitian ini berdasarkan dari latar belakang pendidikan yang memiliki gelar S3 hingga Diploma, umur, dan pengalaman bekerja dalam Biro Yayasan Sosial Sekretariat Daerah Provinsi Jawa Barat. Dengan demikian, dalam penelitian ini hanya diambil 44 orang dari 64 orang.

Penelitian ini merupakan penelitian asosiatif kausal dengan menggunakan pendekatan kuantitatif.

Skala yang digunakan dalam penelitian ini adalah skala Likert.

Tabel 6 Bobot kriteria jawaban skala Likert

\begin{tabular}{|c|c|c|}
\hline Keterangan & Arti & Angka \\
\hline SS & Sangat Setuju & 5 \\
S & Setuju & 4 \\
KS & Kurang Setuju & 3 \\
TS & Tidak Setuju & 2 \\
STS & Sangat Tidak Setuju & 1 \\
\hline
\end{tabular}

\section{ANALISIS DATA}

Validitas merupakan suatu ukuran yang menunjukkan tingkat kevalidan atau kesahihan suatu instrumen. Instrumen yang valid mempunyai validitas tinggi, sedangkan instrumen yang kurang valid berarti memiliki validitas rendah (Arikunto 2006: 168).

Jumlah responden dalam uji validitas ini sebanyak 44 responden sehingga diperoleh nilai $r$ Product Moment $(0,251)$ yang diperoleh dari tingkat kepercayaan $95 \%$ atau taraf signifikansi $5 \%$. Nilai $r$ dari tabel dapat dilihat dalam tabel 14 dengan $\mathrm{Df}=$ Jumlah responden -2 , Maka nilai Df dalam tabel $r$ tersebut adalah 42. 
Tabel 7 Tabel $R$ berdasarkan literatur

\begin{tabular}{|r|c|c|c|c|c|}
\hline \multirow{2}{*}{ DF = n-2 } & \multicolumn{5}{|c|}{ Tingkat Signifikansi Untuk Uji 1 arah } \\
\cline { 2 - 6 } & 0,05 & 0,025 & 0,001 & 0,005 & 0,0005 \\
\hline 1 & 0,9877 & 0,9969 & 0,9995 & 0,9999 & 1 \\
\hline 2 & 0,9 & 0,95 & 0,98 & 0,99 & 0,999 \\
\hline 3 & 0,8054 & 0,8783 & 0,9343 & 0,9587 & 0,9911 \\
\hline 4 & 0,7293 & 0,8114 & 0,8822 & 0,9172 & 0,9741 \\
\hline 5 & 0,6694 & 0,7545 & 0,8329 & 0,8745 & 0,9509 \\
\hline 6 & 0,6215 & 0,7067 & 0,7887 & 0,8343 & 0,9249 \\
\hline 40 & 0,2573 & 0,3044 & 0,3578 & 0,3932 & 0,4896 \\
\hline 41 & 0,2542 & 0,3008 & 0,3536 & 0,3887 & 0,4843 \\
\hline 42 & 0,2512 & 0,2973 & 0,3496 & 0,3843 & 0,4791 \\
\hline
\end{tabular}

Sumber: Sekaran, 2006: 74

Uji validitas ini dilakukan dengan membandingkan $r$ hitung lebih besar dari $r$ tabel Product Moment $(0,251)$. Apabila $r$ hitung bernilai positif, maka pernyataan tersebut dikatakan valid. Berdasarkan hasil uji kuesioner kepada 44 responden diperoleh hasil uji validitas yang tertera pada tabel dibawah ini

Tabel 8 Hasil Uji Validitas Instrumen Variabel Disiplin Kerja

\begin{tabular}{|c|c|c|c|}
\hline No. Item Pernyataan & R. Hitung & R. Tabel & Keterangan \\
\hline DK 1 & 0,612 & 0,251 & Valid \\
\hline DK 2 & 0,532 & 0,251 & Valid \\
\hline DK 3 & 0,602 & 0,251 & Valid \\
\hline DK 4 & 0,414 & 0,251 & Valid \\
\hline DK 5 & 0,762 & 0,251 & Valid \\
\hline DK 6 & 0,674 & 0,251 & Valid \\
\hline DK 7 & 0,618 & 0,251 & Valid \\
\hline DK 8 & 0,489 & 0,251 & Valid \\
\hline DK 9 & 0,653 & 0,251 & Valid \\
\hline DK 10 & 0,611 & 0,251 & Valid \\
\hline DK 11 & 0,400 & 0,251 & Valid \\
\hline DK 12 & 0,328 & 0,251 & Valid \\
\hline DK 13 & 0,581 & 0,251 & Valid \\
\hline
\end{tabular}

Sumber : Data primer yang diolah, 2016

Berdasarkan hasil uji validitas terhadap butir-butir pernyataan variabel disiplin kerja, diketahui bahwa semua pernyataan dinyatakan valid karena memiliki nilai Rhitung > Rtabel sehingga butir pernyataan tersebut tetap digunakan dalam penelitian selanjutnya untuk mengukur disiplin kerja. 


\section{Astadi Pangarso}

\section{Putri Intan Susanti}

\section{Variabel Kinerja pegawai}

Tabel 9 Hasil Uji Validitas Instrumen Variabel Kinerja pegawai

\begin{tabular}{|c|c|c|c|}
\hline $\begin{array}{c}\text { No. Item } \\
\text { Pernyataan }\end{array}$ & R. Hitung & R. Tabel & Keterangan \\
\hline K 1 & 0,726 & 0,251 & Valid \\
\hline K 2 & 0,593 & 0,251 & Valid \\
\hline K 3 & 0,430 & 0,251 & Valid \\
\hline K 4 & 0,827 & 0,251 & Valid \\
\hline K 5 & 0,492 & 0,251 & Valid \\
\hline K 6 & 0,357 & 0,251 & Valid \\
\hline K 7 & 0,524 & 0,251 & Valid \\
\hline K 8 & 0,647 & 0,251 & Valid \\
\hline K 9 & 0,321 & 0,251 & Valid \\
\hline K 10 & 0,477 & 0,251 & Valid \\
\hline K 11 & 0,573 & 0,251 & Valid \\
\hline
\end{tabular}

Sumber : Data primer yang diolah, 2016

Berdasarkan hasil uji validitas terhadap butir-butir pernyataan variabel kinerja, diketahui bahwa semua pernyataan dinyatakan valid karena memiliki nilai Rhitung > Rtabel sehingga butir pernyataan tersebut tetap digunakan dalam penelitian selanjutnya untuk menguji reliabilitas.

Dalam penelitian ini pengujian reliabilitas dilakukan terhadap 44 responden dan jika nilai nilai alpha melebihi 0,6 maka pernyataan variabel tersebut reliabel dan sebaliknya (Ghozali 2011: 48).

Tabel 10 Hasil Perhitungan Uji Reliabilitas Instrumen

\begin{tabular}{|c|c|c|c|c|}
\hline No. & Variabel & $\begin{array}{c}\text { Cronbach's } \\
\text { Alpha }\end{array}$ & $\begin{array}{c}\text { Cronbach's } \\
\text { Alpha Yang } \\
\text { Disyaratkan }\end{array}$ & Keterangan \\
\hline 1 & Disiplin Kerja & 0,808 & 0,6 & Reliabel \\
\hline 2 & Kinerja pegawai & 0,808 & 0,6 & Reliabel \\
\hline
\end{tabular}

Sumber: Data primer yang diolah, 2016

Berdasarkan tabel di atas diketahui bahwa semua variabel penelitian reliabel dan dapat digunakan dalam penelitian.

Uji Normalitas ini dilakukan untuk mengetahui nilai residual yang dihasilkandari regresi terdistribusi secara normal atau tidak (Ghozali, 2009:78). Dalam penelitian ini terdapat dua variabel yang akan dicari normalitasnya, yaitu antara (X) Disiplin kerja dan Kinerja Pegawai (Y). Nilai residual berdistribusi normal merupakan suatu kurva berbentuk lonceng (bellshapedcurve) yang kedua sisinya melebar hingga tidak terhingga. Distribusi tidak normal karna terdapat niali ekstrim dengan menggunakan histogram regression residual. Berikut ini Gambar dari histogram regression: 


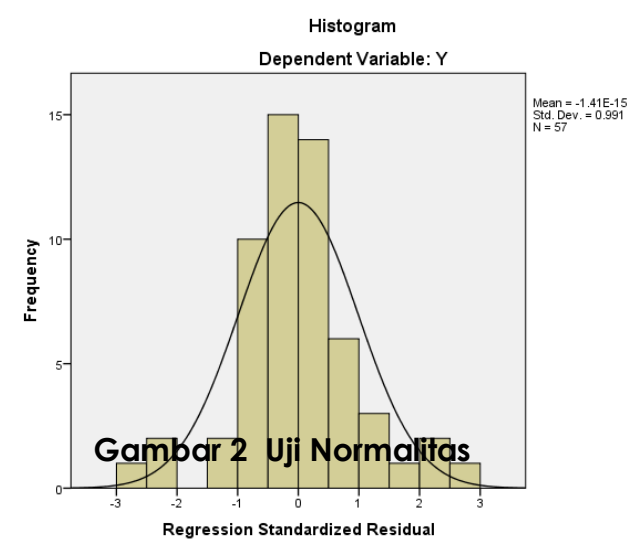

Sumber: Pengolahan Data SPSS 2016

Berdasarkan gambar diatas dapat dikatan bahwa model berdistribusi normal karena kurva membentuk lonceng. Selain itu, pengujian ini dapat dilakukan dengan menggunakan normal probability plot. Normal P-Plot seperti pada gambar 5

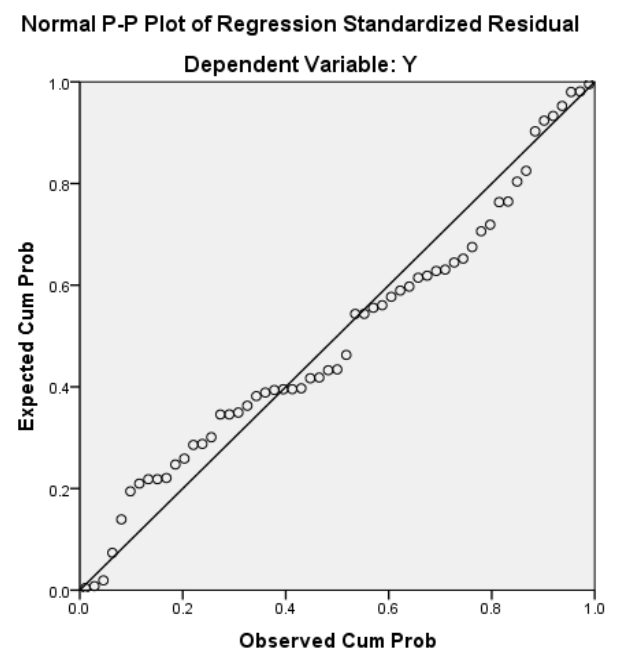

Pada gambar diatas menunjukan pola distribusi yang mendekati normal karena titik-titik menyebar disekitar garis normal serta penyebaranya mengikuti arah garis normal. Untuk selanjutnya dilakukan uji normalitas dengan menggunakan uji One- Sample KolmogorovSmirnov Testhasilnya dapat dilihat pada tabel 11.

Tabel 11 Hasil Uji One- Sample Kolmogorov- Smirnov Test

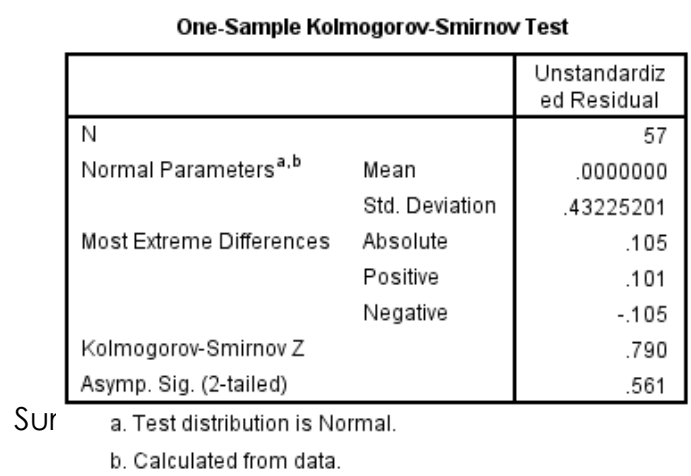




\section{Astadi Pangarso}

\section{Putri Intan Susanti}

Berdasarkan tabel 13 diketahui bahwa nilai signifikan pada uji kolmogorov Smirnov sebesar $0,561>0,05$. Oleh karena itu dapat disimpulkan bahwa data yang berdistribusi normal. Dari tabel di atas dapat disimpulkan bahwa semua variabel adalah normal. Hal ini dapat dilihat dari tingkat signifikansi semua di atas 0,05.

Uji heterokedastisitas digunakan untuk melihat apakah terdapat ketidaksamaan varians dari residual satu pengamatan ke pengamatan yang lain. Model regresi yang memenuhi persyaratan adalah dimana terdapat kesamaan varians dari residual satu pengamatan ke pengamatan yang lain tetap atau disebut homokesdastisitas. Berikut ini hasil gambar dari scatterplot menggunakan SPSS Versi 23.0.

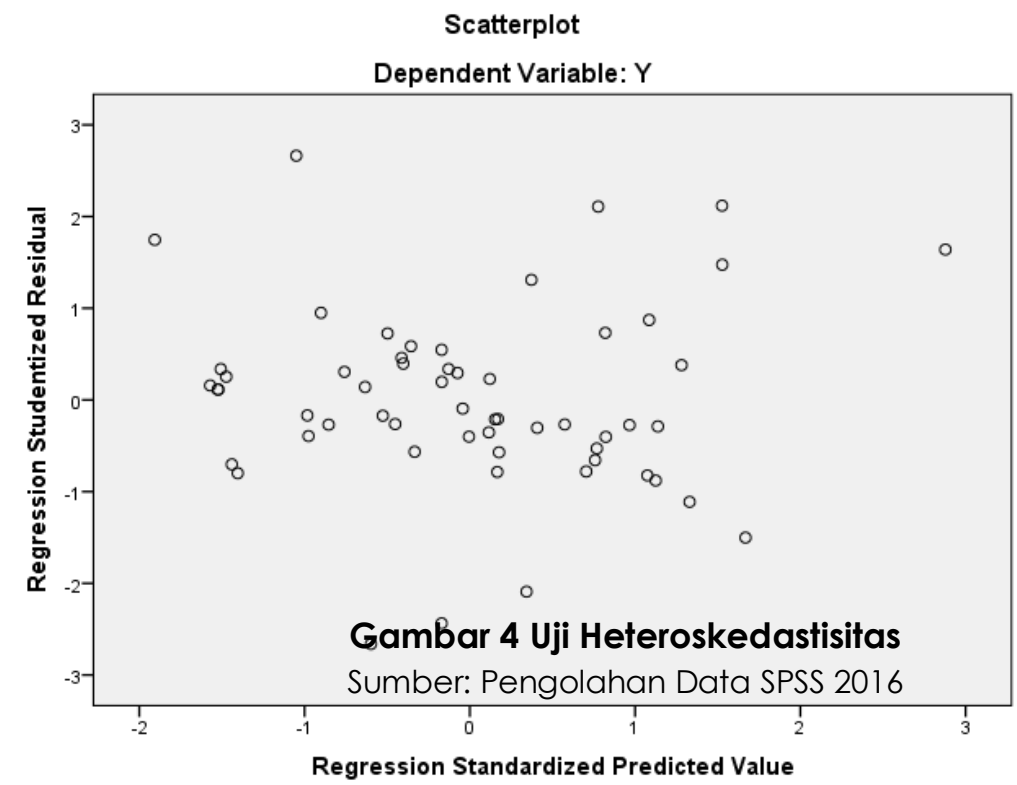

Gambar 4 menunjukan diagram terpencar dan tidak membentuk pola tertentu, maka regresi tidak mengalami gangguan heteroskedastisitas.

Uji $†$ (test of significance individual parameter) digunakan untuk mengetahui pengaruh signifikan yang diberikan oleh variabel bebas yaitu disiplin kerja terhadap variabel terikat, yaitu kinerja pegawai. Sebelum melakukan uji T, dilakukan pencarian nilai T tabel. Berikut nilai untuk T tabel berdasarkan literatur: 
Tabel 12 Tabel T berdasarkan literatur

\begin{tabular}{|c|c|c|c|c|c|}
\hline d.f. & $5 \%$ & $2 \%$ & $1 \%$ & $0,20 \%$ & $0,10 \%$ \\
\hline 1 & 12,706 & 31,821 & 63,657 & 318,309 & 636,619 \\
\hline 2 & 4,303 & 6,965 & 9,925 & 22,327 & 31,599 \\
\hline 3 & 3,182 & 4,541 & 5,841 & 10,215 & 12,924 \\
\hline 4 & 2,776 & 3,747 & 4,604 & 7,173 & 8,61 \\
\hline 5 & 2,571 & 3,365 & 4,032 & 5,893 & 6,869 \\
\hline 6 & 2,447 & 3,143 & 3,707 & 5,208 & 5,959 \\
\hline 7 & 2,365 & 2,998 & 3,499 & 4,785 & 5,408 \\
\hline 8 & 2,306 & 2,896 & 3,355 & 4,501 & 5,041 \\
\hline 40 & 2,021 & 2,423 & 2,704 & 3,307 & 3,551 \\
\hline 41 & 2,02 & 2,421 & 2,701 & 3,301 & 3,544 \\
\hline 42 & 2,018 & 2,418 & 2,698 & 3,296 & 3,538 \\
\hline 43 & 2,017 & 2,416 & 2,695 & 3,291 & 3,532 \\
\hline \multicolumn{7}{|c|}{ Sumber: Sekaran, $2006: 112$} \\
\end{tabular}

Jumlah responden dalam uji validitas ini sebanyak 44 responden sehingga diperoleh nilai tabel T sebesar 2,018 yang diperoleh dari tingkat kepercayaan $95 \%$ atau taraf signifikansi 5 \%. Nilai $r$ dari tabel dapat dilihat dalam tabel 18 dengan Df $=$ Jumlah responden -2 , Maka nilai Df dalam tabel $r$ tersebut adalah 42. Hasil Output SPSS yang berkaitan dengan uji $\dagger$ pada tabel 13 di bawah ini:

\section{Tabel 13 Uji $\dagger$}

\begin{tabular}{|c|c|c|c|c|c|}
\hline \multirow{2}{*}{ Model } & \multicolumn{2}{|c|}{$\begin{array}{c}\text { Unstandardized } \\
\text { Coefficients }\end{array}$} & $\begin{array}{c}\text { Standardized } \\
\text { Coefficients }\end{array}$ & T & Sig. \\
\cline { 2 - 6 } Model & B & Std. Error & Beta & t & Sig. \\
\hline I Disiplin Kerja (X) & .646 & .463 & .169 \\
& .849 & .110 & .745 & 7.726 & .000 \\
\hline
\end{tabular}

Dari tabel di atas dapat dilihat bahwa nilai thitung adalah 7,726 , yang mana nilainya lebih besar dari ttabel yang nilainya 2,018 dan dengan nilai signifikansi yang dihasilkan variabel disiplin kerja adalah 0,00 dan niliai ini < 0,05, hipotesis yang menyatakan bahwa variabel disiplin kerja mempengaruhi kinerja pegawai Biro Pelayanan Sosial Dasar Sekretariat Daerah Provinsi Jawa Barat bisa diterima kebenarannya.

Analisis regresi linier sederhana digunakan untuk mengetahui hubungan kausal antara variabel bebas yaitu variabel disiplin kerja dengan variabel terikat yaitu kinerja pegawai. Berdasarkan perhitungan atas data yang telah dikumpulkan dengan menggunakan program SPSS for windows version 23.0 maka diperoleh output pengujian data sebagai berikut: 


\section{Astadi Pangarso}

\section{Putri Intan Susanti}

Tabel 14 Output Olahan Regresi Linier Sederhana

Coefficientsa

\begin{tabular}{|c|c|c|c|c|c|c|c|c|c|c|c|c|}
\hline \multirow[t]{2}{*}{ Model } & \multicolumn{2}{|c|}{$\begin{array}{c}\text { Unstandardize } \\
\text { d } \\
\text { Coefficients }\end{array}$} & \multirow{2}{*}{$\begin{array}{c}\begin{array}{c}\text { Standardiz } \\
\text { ed }\end{array} \\
\text { Coefficient } \\
\text { Beta }\end{array}$} & \multirow{2}{*}{ t } & \multirow{2}{*}{ Sig. } & \multicolumn{2}{|c|}{$\begin{array}{c}95.0 \% \\
\text { Confidence } \\
\text { Interval for B }\end{array}$} & \multicolumn{3}{|c|}{ Correlations } & \multicolumn{2}{|c|}{$\begin{array}{c}\text { Collinearity } \\
\text { Statistics }\end{array}$} \\
\hline & B & $\begin{array}{l}\text { Std. } \\
\text { Error }\end{array}$ & & & & Lowe & Upper & $\begin{array}{l}\text { Zero- } \\
\text { order }\end{array}$ & Partic & Part & Toleran & VIF \\
\hline \multirow[t]{2}{*}{$\begin{array}{c}1 \text { (Constant) } \\
\text { Disiplin Kerja (X) }\end{array}$} & .646 & .463 & & 1.396 & .169 & -.284 & 1.577 & & & & & \\
\hline & .849 & .110 & .745 & 7.726 & .000 & .628 & 1.070 & .745 & .745 & .745 & 1.000 & 1.00 \\
\hline
\end{tabular}

a. Dependent Variable: Kinerja pegawai $(Y)$

Berdasarkan perhitungan dengan menggunakan program SPSS for windows version 23.0 maka diperoleh hasil-hasil pengujian sebagai mana terlihat bisa dihasilkan formula regresi linier sebagai berikut:

$Y=a+\square X$

$Y=0,646+0,849 X$

Data di atas menunjukkan bahwa pengaruh disiplin kerja $(X)$ terhadap kinerja pegawai adalah positif sebesar 0,849, Dengan demikian jika variabel disiplin kerja mengalami kenaikan 0,849 maka variabel kinerja pegawai juga akan mengalami kenaikan sejumlah 0,646 .

Koefisien determinasi merupakan koefisien yang nilainya dimaksudkan untuk mengetahui seberapa besar variasi perubahan dalam satu variabel independen. Pengolahan data untuk menentukan koefisien determinasi bisa dilihat dari gambar output SPSS versi 23.0:

Tabel 15. Koefisien Determinasi Model Summaryb

\begin{tabular}{|c|c|c|c|c|c|c|c|c|c|}
\hline \multirow[b]{2}{*}{$\begin{array}{l}\text { Model } \\
\text { Model }\end{array}$} & \multirow[b]{2}{*}{$\begin{array}{l}\mathbf{R} \\
\mathbf{R}\end{array}$} & \multirow[b]{2}{*}{ R Square } & \multirow[b]{2}{*}{$\begin{array}{l}\text { Adjusted R } \\
\text { Square }\end{array}$} & \multirow[b]{2}{*}{$\begin{array}{l}\text { Std. Error of the } \\
\text { Estimate }\end{array}$} & \multicolumn{5}{|c|}{ Change Statistics } \\
\hline & & & & & R Square & F Change & df1 & $\mathbf{N}$ & $\begin{array}{c}\text { Sig. } \mathbf{F} \\
\text { Change }\end{array}$ \\
\hline 1 & $.745 a$ & .554 & .545 & .32875 & .554 & 59.692 & 1 & 44 & .000 \\
\hline
\end{tabular}

a. Predictors: (Constant), Disiplin Kerja (X)

b. Dependent Variable: Kinerja pegawai $(Y)$ 
Output pada tabel di atas menunjukkan bahwa nilai $R$ (korelasi) yang dihasilkan adalah 0,745, maka dapat dikatakan bahwa disiplin kerja dan kinerja pegawai berhubungan positif sebesar $74,5 \%$. Sedangkan koefisien determinasi R2 (R Square) adalah 0,554, yang artinya adalah kemampuan variabel disiplin kerja dalam mempengaruhi kinerja pegawai di Biro Pelayanan Sosial Dasar Sekretariat Daerah Provinsi Jawa Barat adalah sebesar $55,4 \%$ sedangkan $44,6 \%$ adalah sumbangsih dari faktor-faktor lain yang tidak diamati dalam penelitian ini.

\section{PEMBAHASAN DAN KESIMPULAN}

Analisis data di atas menunjukkan bahwa disiplin kerja $(\mathrm{X})$ memiliki pengaruh yang signifikan positif terhadap kinerja pegawai Biro Pelayanan Sosial Dasar Sekretariat Daerah Provinsi Jawa Barat. Hal ini ditunjukkan dengan beberapa uji yang dilakukan terhadap variabel disiplin kerja. Disiplin kerja pada dasarnya memiliki peranan tinggi dalam meningkatkan kinerja pegawai. Disiplin kerja yang tinggi harus selalu dijaga, bahkan harus ditingkatkan guna lebih baik. Pegawai yang memiliki disiplin kerja yang baik diharapkan akan mampu berusaha semaksimal mungkin untuk menyelesaikan pekerjaannya, sehingga dapat menghasilkan kinerja yang optimal bagi perusahaan. Pegawai yang disiplin cenderung tepat waktu dalam melaksanakan prosedur yang telah ditetapkan dan memiliki tanggung jawab yang tinggi.

Hal ini berkaitan dengan teori disiplin kerja menurut Soejono (1986: 65) yang menyatakan bahwa Disiplin yang baik yakni mencerminkan besarnya rasa tanggung jawab seseorang terhadap tugas-tugas yang diberikan kepadanya. Hal tersebut dapat mendorong timbulnya peningkatan kinerja serta tercapainya tujuan perusahaan, pegawai, dan masyarakat. Dengan kata lain, disiplin kerja merupakan modal utama yang amat menentukan terhadap tingkat kinerja pegawai.

Indikator disiplin kerja dalam penelitian ini adalah ketaatan pada peraturan dan kesadaran pribadi. Ketaatan pada peraturan meliputi ketepatan waktu, serta pelaksanaan prosedur yang telah ditentukan. Ketepatan waktu adalah bentuk disiplin kerja pegawai dengan datang tepat waktu, tertib, dan teratur. Pelaksanaan prosedur yang telah ditetapkan menunjukkan bahwa pegawai memiliki disiplin kerja yang baik. Kesadaran pribadi meliputi tingkat kerapian berpakaian di tempat kerja, memiliki tanggung jawab tinggi, serta tingkat kualitas yang dihasilkan. Berpakaian rapi di tempat kerja merupakan salah satu indikasi adanya disiplin kerja. Pekerjaan yang dilaksanakan dengan penuh rasa tanggung jawab, maka kualitas yang dihasilkan pun akan memuaskan karena sesuai dengan standar yang telah ditentukan.

Dari penjelasan tersebut dapat disimpulkan bahwa adanya disiplin kerja yang baik maka akan menghasilkan kinerja pegawai yang baik, sebaliknya apabila disiplin kerja kurang baik akan menghasilkan kinerja pegawai yang kurang baik pula. Penelitian ini juga didukung dengan penelitian yang dilakukan oleh Zesbendri dan Ariyanti (2005) yang menunjukkan bahwa disiplin kerja berpengaruh positif signifikan terhadap kinerja pegawai.

Selanjutnya, disiplin kerja mempunyai pengaruh yang sangat kuat dalam mempengaruhi terciptanya kinerja pegawai Biro Pelayanan Sosial Dasar Sekretariat Daerah Provinsi Jawa Barat secara optimal, nilai $R$ (korelasi) yang dihasilkan adalah 0,745 , maka dapat dikatakan bahwa disiplin kerja dan kinerja pegawai berhubungan positif sebesar $74,5 \%$. Sedangkan 


\section{Astadi Pangarso}

\section{Putri Intan Susanti}

koefisien determinasi R2 (R Square) adalah 0,554, yang artinya adalah kemampuan variabel disiplin kerja dalam mempengaruhi kinerja pegawai di Biro Pelayanan Sosial Dasar Sekretariat Daerah Provinsi Jawa Barat. adalah sebesar 55,4\% sedangkan $44,6 \%$ adalah sumbangsih dari faktor-faktor lain yang tidak diamati dalam penelitian ini. Dalam analisis korelasi menunjukkan bahwa hubungan yang sangat erat antara disiplin kerja dengan kinerja pegawai, hubungan tersebut dapat dijelaskan dengan prosentase sebesar $74,5 \%$.

Hal ini sangat wajar mengingat pekerjaan yang dikerjakan oleh pegawai Biro Pelayanan Sosial Dasar Sekretariat Daerah Provinsi Jawa Barat tidaklah mudah, maka diperlukannya beberapa aspek yang menyebabkan pegawai puas terhadap pekerjaan yang dilakukan, sehingga nantinya akan berdampak pada kinerja yang optimal dalam perusahaan. Sesuai dengan teori yang dikemukakan oleh Robbin (2001) bahwa ada beberapa aspek yang mempengaruhi disiplin kerja seorang pegawai, yaitu:

1. Kerja yang secara mental menantang

2. Kondisi kerja yang mendukung

3. Ganjaran yang pantas

4. Kesesuaian kepribadian dengan pekerjaan

5. Rekan kerja dan pimpinan yang mendukung

Kemudian kinerja pegawai $(Y)$ dapat dijelaskan oleh disiplin kerja melalui regresi $Y=0,646+$ $0,849 \mathrm{X}$. Hal ini menunjukkan pengaruh disiplin kerja $(\mathrm{X})$ terhadap kinerja pegawai $(\mathrm{Y}$ ) adalah positif sebesar 0,849 , Dengan demikian jika variabel disiplin kerja mengalami kenaikan 0,849 maka variabel kinerja pegawai juga akan mengalami kenaikan sejumlah 0,646. Hal ini, menunjukkan bahwa ketika pegawai merasa sangat puas dengan pekerjaannya maka mereka akan melakukan kinerja dengan optimal.

Ketika semua aspek disiplin kerja yang berkaitan dengan pegawai dapat terpenuhi oleh perusahaan, maka pegawai akan melakukan optimalisasi kerja untuk perusahaan. (Purwanto dan Wahyuddin $2007:$ 42)

Berdasarkan hasil penelitian, maka dapat disimpulkan bahwa:

1. Disiplin kerja $(X)$ memiliki pengaruh yang signifikan positif terhadap kinerja Biro Pelayanan Sosial Dasar Sekretariat Daerah Provinsi Jawa Barat. Hal ini ditunjukkan dengan beberapa uji yang dilakukan terhadap variabel disiplin kerja.

\section{Implikasi dan Keterbatasan}

1. Bagi Biro Pelayanan Sosial Dasar Sekretariat Daerah Provinsi Jawa Barat supaya mempertahankan dan meningkatkan pengaruh disiplin kerja terhadap kinerja dengan cara mempertahankan aspek-aspek disiplin kerja yang telah ada saat ini dan selalu melakukan pengawasan terhadap kinerja pegawainya

2. Bagi penelitian berikutnya yang ingin melakukan penelitian tentang kinerja pegawai, supaya menambah variabel selain disiplin kerja dalam mempengaruhi kinerja pegawai, sehingga penelitian berikutnya lebih akurat dalam melakukan pengukuran terhadap kinerja pegawai. Hal ini juga menunjukkan keterbatasan konteks dalam penelitian 
(tempat, waktu, banyaknya variabel yang dibahas, metode pengolahan data dan kedalaman analisis).

\section{DAFTAR PUSTAKA}

Arikunto, Suharsimi. 2002. Prosedur Penelitian Suatu Pendekatan Praktek.Jakarta: PT. RINEKA CIPTA.

Azwar, S. 2009. Sikap Manusia, Teori dan Pengukurannya. Jakarta: PustakaPelajar

Amran. 2009. "Pengaruh Disiplin Kerja Terhadap Kinerja Pegawai kantor Departemen Sosial Kabupaten Gorontalo". Dalam Jurnal Ichsan Gorontalo, Volume 4 No. 2. Hal 23972413. Gorontalo: Universitas Ichsan Gorontalo.

Fornell, C. dan Larcker, D.F. 1981. Evaluating Structural Equation Models with Unobservable Variables and Measurement Error. Journal of Marketing Research, 18, 39-50

Ghozali, Imam. 2009. Aplikasi Analisis Multivariate Dengan Program SPSS, Edisi Keempat. Semarang: Penerbit Universitas Diponegoro.

Ghozali, Imam. Aplikasi Analisis Multivariate dengan Program SPSS.c Semarang : Badan Penerbit UNDIP, 2006.

Ghozali, Imam. 2011. Aplikasi Analisis Multivariate dengan Program IBM SPSS19. Semarang: Universitas Diponegoro.

George, J, \& Jones, G. 2002. Organizational Behavior (3rd ed). USA: Prentice-Hall.

Grvenberg, B. 1980. The Happy Worker: An Analisys of Educational and Occupational Difference in Determinants of Job Satisfaction. American Journal of Sociology. 85. 247-271.

Hardiyanto, Yudi, dkk 2003."Perancangan dan Pembuatan Sistem Informasi Pengukuran Kinerja Pemasaran dengan Metode Balanced Scorecard Studi Kasus PT. Semen Gresik". Jurnal

Hasibuan, Malayu. 2004. Manajemen Sumber Daya Manusia. Jakarta: PT BumiAksara.

Kreitner R, \& kinicki, A. 2001. Organizational Behavior. Fith Edition, International Edition, MC graw-Hill Companies, Inc.

Kuncoro, Mudrajad. 2003. Metode Riset untuk Bisnis dan Ekonomi. Jakarta: Erlangga.

Logahan, Jerry Marcellinus. 2009. "Pengaruh Lingkungan Kerja dan Stres Pekerjaan Terhadap Kinerja Pekerja di PT Nemanac Rendem". Tarakanita.

Mangkunegara, Anwar Prabu. 2004. Manajemen Sumber Daya Manusia Perusahaan. Bandung: PT Remaja Rosdakarya.

Mathis, R dan Jackson, W. 2006. Human Resources Development (Track MBAseries/terjemahan). Jakarta; Prestasi Pustaka

Meta, Nandha. 2013. Pengaruh Disiplin Kerja dan Kepemimpinan Terhadap Kinerja Karyawan Pada PT. Pustaka Rizki Putra Semarang. Tesis. Fakultas IImu Sosial dan Politik Universitas Diponegoro Semarang

Mudiartha Utama, Wayan. 2001. Manajemen Sumber Daya Manusia. Denpasar : UPT Penerbit Universitas Udayana

Nugroho, Agung Bhuono. Strategi Jitu Memilih Metode Statistika Penelitian DenganMenggunakan SPSS. Yogyakarta: CV. Andi Offset, 2005.

Pangarso, Astadi. Asri, Fara Dila Agitha. 2014. "Dominant Factor Affecting Marketing Employee Discipline In Publishing Company". Proceeding. the 2014 International Conference in Organization Innovation (ICOI) 


\section{Astadi Pangarso}

\section{Putri Intan Susanti}

Prasetyo Utomo. 2008, Analisis Pengaruh Pemberdayaan dan Lingkungan Kerja Terhadap Kinerja Karyawan, Semarang: Fakultas Ekonomi Universitas Semarang.

Rahmatullah, Reska. 2003. "Analisis Pengaruh Budaya Organisasi, Kepuasan Kerja, Gaya Kepemimpinan Terhadap Kinerja Karyawan PT Penerbit Erlangga Cabang Palembang".

Riduwan dan Sunarto. Pengantar Statistika Untuk Pendidikan, Sosial, Ekonomi, Komunikasi dan Bisnis (lengkap dengan aplikasi SPSS 14), Cet ke-1. Bandung: Alfabeta, Agustus 2007.

Riduwan, Dasar-dasar Statistika, Bandung: CV Alfabeta, 2008.

Rivai, Veithzal dan Basri. 2005. Performance Appraisal: Sistem Yang Tepat Untuk Menilai Kinerja Karyawan Dan Meningkatkan Daya Saing Perusahaan. Jakarta PT RAJA GRAFINDO PERSADA.

Robbins, Stephen P. 2006. Perilaku Organisasi. Edisi Kesepuluh. PT Indeks : Kelompok Gramedia.

Robert dan Steven J. Taylor. 1992. Pengantar Metoda Penelitian Kualitatif.

Surabaya: Usaha Nasional

Santosa, Purbayu Budi dan Ashari. 2005. Analisis Statistik dengan MicrosoftExcel dan SPSS. Yogyakarta: Penerbit Andi.

Setiyawan, Budi dan Waridin. 2006. Pengaruh Disiplin Kerja Karyawan Dan Budaya Organisasi Terhadap Kinerja Di Divisi Radiologi RSUP Dokter Kariadi Semarang. JRBI . Vol 2. No 2. Hal: 181-198.

Simamora Henry. 1997. Manajemen Sumber Daya Manusia. Cetakan kedua.Yogyakarta: STIE TKPN

Sugiyono. 2010. MetodePenelitian Kuantitatif Kualitatif \& RND.Bandung:CV.ALFABETA

Suwanto,2011.Asas-Asas Manajemen Sumber Daya Manusia.Suci Press: Bandung

Sutrisno, Edy. 2010. Manajemen Sumber Daya Manusia. Jakarta: PT PrenadaMedia Group.

Umar, Husein. 2005, Metodologi Penelitian Untuk Skripsi dan Tesis Bisnis, Jakarta: PT. Gramedia Pustaka. 